\title{
KANT E O RESGATE DO BEM NA NATUREZA HUMANA DECAÍDA
}

\author{
Letícia Machado Pinheiro ${ }^{1}$
}

RESUMO: este artigo tem como propósito examinar os argumentos de Kant quanto à possibilidade do restabelecimento do bem face ao mal radical na natureza humana. A investigação aqui proposta toma como ponto de partida e foco central a afirmação kantiana de que intenção ou máxima suprema está corrompida pelo mal, e busca, a partir das consequências de tal constatação e dos argumentos fornecidos por Kant, delinear as possibilidades e o caráter do restabelecimento do bem no interior de tal intenção ${ }^{2}$.

PALAVRAS-CHAVE: Bem. Mal. Intenção. Progresso moral.

A argumentação kantiana acerca da ruína moral do homem e da necessidade de um progresso toma como pano de fundo o conflito entre duas possibilidades de acolhimento da lei da moralidade: a disposição para o bem [Anlage zum Guten] e a propensão para o mal [Hang zum Bösen]. A disposição para o bem diz respeito à capacidade de agir por dever em termos kantianos, isto é, de edificar uma ação tomando a lei moral como móbil suficiente. A propensão para o mal é a tendência de tomar móbiles exteriores à moralidade para executar ações pertencentes ao domínio moral ${ }^{3}$. Malgrado Kant admita um conflito entre a disposição para o bem e a propensão para o mal, no interior do ânimo humano,

${ }^{1}$ Acadêmica do Curso de Doutorado em Filosofia da Universidade Federal do Rio Grande do Sul (UFRGS). Bolsista do CNPq. leticiamachadopinheiro@yahoo.com.br

${ }^{2}$ Abreviaturas utilizadas: MS (Die Metaphysik der Sitten); Rel (Die Religion innerhalb der Grenzen der bloßen Vernunft); KpV (Kritik derpraktischen Vernunft). Para esta última obra, foi utilizada (conforme consta na bibliografia) a tradução de Valério Rohden.

${ }^{3}$ Disso, porém, não se segue que a ação boa seja destituída de motivação empírica e que a dita como má não tome alguma relevância moral. Segundo Kant, " [...] a diferença de se o homem é bom ou mau não tem que residir na diferença dos móbiles que ele acolhe na sua máxima (não na sua matéria), mas, sim, na subordinação (forma da máxima): de qual dos dois móbiles ele faz a condição do outro" ["Also muß der Unterschied, ob der Mensch gut oder böse sei, nicht in dem Unterschiede der Triebfedern, die er in seine Maxime aufnimmt (nicht in dieser ihrer Materie), sondern in der Unterordnung (der Form derselben) liegen: welche von beiden er zur Bedingung der andern macht'] (Rel, 1793,36). Kant edifica a sua argumentação acerca do bem e do mal nos termos do grau de suficiência que o homem concede à lei. Conforme a sua argumentação, o homem inevitavelmente é afetado quer pela lei da moralidade, quer por móbiles sensíveis, de sorte que o seu caráter moral não pode ser instituído em dependência do móbil que ele adota, pois é afetado por móbiles advindos dessas duas fontes, mas do valor primordial ou grau de importância supremo conferido a um deles (no sentido de que a posse de semelhante móbil seja suficiente para edificar a ação). Uma abordagem mais detalhada dessa questão 
bem e mal não coexistem na natureza humana como dois princípios opostos em pé de igualdade. Há, por assim dizer, uma precedência do bem, uma vez que a disposição é definida como originária [ursprüngliche]. Dizer que a disposição é originária ao homem significa afirmar que ela faz parte ou vem a se constituir na natureza humana, de modo que não é passível de ser extirpada, porque tal natureza não seria possível (ou concebível) sem tal disposição (Rel, 1793, 28).

Porquanto haja essa identificação direta entre a disposição para o bem e a natureza humana, ela não se dá em termos tão vigorosos, a ponto de impedir que o homem enverede para o mal. Ocorre que ser portador de uma disposição para o bem, mesmo que originária, não representa a posse do próprio bem. Tal disposição significa tão-só "[...] a suscetibilidade [Empfänglichkeit] ao respeito pela lei moral como um móbil por si mesmo suficiente ao arbítrio"4 (Rel, 1793, 27). Tal suscetibilidade "[...] por si não constitui ainda um fim da disposição natural, mas somente na medida em que é móbil para o arbítrio" (Rel, 1793, 27). Dá-se que, até não efetivarmos essa disposição (mediante a tomada da lei moral como móbil suficiente para o arbítrio), somos apenas "suscetíveis", de modo que a finalidade de nossa disposição não está ainda concretizada.

O campo de embate entre o bem e o mal, assim como o domínio no qual apenas um deles pode se consolidar, é aquele da intenção [Gesinnung]. Daí porque todo o mecanismo descritivo da investigação kantiana acerca do mal e da complexidade de um futuro progresso moral do humano repousa no conceito de intenção - conceito também convencionado por Kant como máxima suprema. A argumentação está centrada no plano da intenção, porque bem e mal, pelo ponto de vista kantiano e no que tange à moralidade, dizem respeito a um modo de acolhimento ou recepção da lei moral por parte do agente, cuja efetivação se dá no âmbito intencional. A complexidade se impõe, conforme veremos, porque os termos a partir dos quais Kant define a intenção, associados ao fato de ele admitir que o homem é mau, dificultam a plausibilidade de um progresso moral ou resgate do bem originário.

\section{I- INTENÇÃo [GESINNUNG]}

Kant entende por intenção “[...] o primeiro fundamento subjetivo da adoção de máximas; que somente pode ser único e referir-se universalmente ao

pode ser encontrada em: PINHEIRO, Letícia Machado. "Kant e o mal moral: a insuficiência da lei como móbil para o arbítrio”. Studia kantiana. Santa Maria: Pallotti, 2009, p.141-153.

4 “[...] die Anlage für die Persönlichkeit ist die Empfänglichkeit der Achtung für das moralische Gesetz, als einer für sich hinreichenden Triebfeder der Willkür [...]”

5 “[...] welches für sich noch nicht einen Zweck der Naturanlage ausmacht, sondern nur sofern es Triebfeder der Willkür ist”. 
uso integral da liberdade" (Rel, 1793, 25). A Gesinnung (ou intenção), Kant a situa como um primeiro fundamento, porque é a partir dela que se impõe o ânimo moral do agente. Ela é um "primeiro fundamento", porque está sempre presente no ponto de partida subjetivo fundante da ação. Kant observa que a intenção não pode ser acessada, uma vez que, enquanto primeiro fundamento, ela mesma é uma máxima e, sendo uma máxima, a fim de se ter acesso a ela, seria preciso aduzir outra máxima na qual tivesse contida uma intenção, que deveria, por seu turno, ter o seu fundamento (cf. Rel, 1793, 25). Ele ainda acrescenta que não podemos conhecer a causa de por que a intenção é boa ou má, visto que ela se constitui em um ato de liberdade ${ }^{7}$ (cf. Rel, 1793, 25).

O mais fundamental e característico do conceito de intenção é o fato de ela atuar como uma máxima suprema e de ser única. Ela é uma máxima suprema, porque, enquanto um primeiro fundamento de adoção de máximas, todas as máximas derivam dela e, por essa sua derivação, se constituem, em termos de maldade ou bondade, tal como ela. Quer dizer, se a intenção for boa, as máximas dela derivadas serão forçosamente boas; se for má, todas as máximas serão más. É sempre a mesma intenção que está subjacente a todas as ações referentes à moralidade (por isso, ela é uma máxima suprema). Outro ponto importante é o da unicidade da intenção. Kant fala que a intenção é "única" e tal unicidade compreende dois significados: um, existe apenas uma intenção ou máxima suprema; outro, ela é, relativamente à sua qualificação, invariável, ou seja, boa ou má.

Kant, nesse sentido, se contrapõe aos chamados latitudinários sincretistas, os quais defendem que a intenção moral é boa e má simultaneamente, por vezes boa e, outras, má $^{8}$ (cf. Rel, 1793, 22). Tal admissão, pelo ponto de vista kantiano,

6 “[...] der erste subjective Grund der Annehmung der Maximen, kann nur reine einzige sein und geht allgemein auf den ganzen Gebrauch der Freiheit". Tratamos mais amplamente dessa questão no artigo "O conceito kantiano de intenção <<Gesinnung $>>$ em 'Sobre o mal radical na natureza humana"”. Revista Portuguesa de Filosofia. Braga - Portugal, V. 61, n.3-4, pp. 1019-1026, 2005.

${ }^{7}$ Gordon Michalson observa, a esse propósito, que “[...] o termo "intenção” na filosofia moral de Kant não caracteriza realmente um ponto fixo no interior da natureza humana que é revelado no curso de avaliação moral. Em vez disso, o termo simplesmente desempenha a função de uma ficção útil projetada para proteger duas das idéias mais importantes de Kant: a unidade final da agência moral e o caráter indecifrável da liberdade" (1990, p. 61) [“The term 'disposition' in Kant's moral philosophy does not really characterize a fixed point within human nature that is disclosed in the course of moral valuation. Instead, the term simply plays a role of a useful fiction designed to protect two of Kant's most important insights: the ultimate unity of moral agency and the indecipherable character of freedom”].

8 "Mas importa muito à doutrina dos costumes [Sittenlehre] em geral não admitir, na medida do possível, nenhum meio termo moral, nem nas ações (adiaphora) nem nos caracteres humanos: porque em tal ambiguidade todas as máximas correm o risco de perder a sua determinação e firmeza" (Rel, 1793, 22) ["Es liegt aber der Sittenlehre überhaupt viel daran, keine moralische Mittelding werder in 
frutificaria em uma perda de solidez e firmeza no âmbito da adoção de máximas ${ }^{9}$, pois não haveria um comprometimento do agente nem como bem, nem com o mal. "A disposição moral [diz Kant] está necessariamente vinculada a uma consciência da determinação da vontade imediatamente pela lę" (KpV, 2002, 210). Se existe de fato (e no sentido forte do termo) um comprometimento de agir sob a influência da lei, não há espaço para, na ação seguinte, atuar de maneira a desqualificar tal influência. $\mathrm{O}$ indivíduo precisaria, para cada ato, assumir ou não uma aliança com a lei enquanto móbil suficiente, de maneira que tal pacto - pela sua instabilidade - resultaria totalmente banalizado. Os modos de adotar a lei que resultam no bem ou no mal são de tal maneira distintos que não podem ser assumidos concomitantemente, no ânimo de um mesmo agente.

Kant, portanto, é um rigorista no sentido mais castiço do termo: concebe o homem como totalmente mau ou totalmente bom. Não admite meio-termo, ou seja, que o homem possa ser bom e mau ao mesmo tempo, ou bom em algumas ações e mau noutras. Ele é rigorosamente bom ou é mau. A máxima suprema ou intenção não é passível de ser escolhida ou refeita a todo o momento. A intenção, tal como Kant a define, representa, enfim, um pacto com um determinado modo de incorporar a lei da moralidade que, pela sua intensidade e firmeza, não pode ser alterado de um caso para outro como quem troca de roupagem. Trata-se de um comprometimento vigoroso com um modo de acolher ou abordar a lei da moralidade, modo a partir do qual se impõe o bem ou o mal.

Kant delineia a índole da intenção humana e, por conseguinte, do caráter moral do homem, assim como os pressupostos para a sua reabilitação, na seguinte passagem:

Esse mal é radical porque corrompe [verdirbt] o fundamento de todas as máximas; ao mesmo tempo também, como propensão natural [natürlicher Hang $]^{10}$, não pode ser exterminado mediante forças humanas; porque tal extermínio só poderia dar-se através de máximas boas, as quais não encontram lugar quando o fundamento subjetivo supremo de todas as máximas se supõe

Handlungen (adiaphora) noch in menschlichen Charakteren, so lange es möglich ist, einzuräumen: weil bei einer solchen Doppelsinnigkeit alle Maximen Gefahr laufen, ihre Bestimmtheit und Festigkeit einzubüßen”].

${ }^{9}$ Kant denomina a propensão de natural, porque a concebe como pertencente ao caráter da espécie humana, isto é, enquanto inerente a todo o homem - não há nenhuma denotação determinística.

10 "Dieses Böse ist radical, weil es den Grund aller Maximen verdirbt; zugleich auch als natürlicher Hang durch menschliche Kräfte nicht zu vertilgen, weil dieses nur durch gute Maximen geschehen könnte, welches, wenn der oberste subjective Grund aller Maximen als verderbt vorausgesetzt wird, nicht statt finden kann; gleichwohl aber muß er zu überwiegen möglich sein, weil er in dem Menschen als frei handelndem Wesen angetroffen wird". 
corrompido; não obstante, precisa ser possível dominá-lo [überviegen], porque se encontra no homem como um ser que age livremente. ${ }^{11}$ (Rel, 1793, 37).

O cenário argumentativo é o seguinte: o fundamento de adoção de máximas, isto é, a máxima suprema ou intenção, está corrompido pelo mal. Aliás, o mal é designado como radical por ter pervertido a raiz do operar - a intenção ou primeiro fundamento de adoção de máximas. Com a corrupção da intenção ou máxima suprema pelo mal, todas as máximas humanas são por consequência más e, portanto, o homem é mau. Segundo Kant, a proposição "[...] o homem é mau [der Mensch ist böse] não pode querer dizer outra coisa senão que ele é consciente da lei moral e, contudo, acolheu na sua máxima o desvio (ocasional) da mesma"12 (Rel, 1793, 32). O extermínio do mal (acrescenta Kant) não é possível, uma vez que ele só pode se dar mediante a instauração de máximas boas, o que supõe uma máxima suprema boa, isto é, uma intenção que conceda à lei da moralidade o estatuto de móbil suficiente para a edificação do agir.

A par desse panorama sombrio, Kant, todavia, afirma que é necessário que seja possível o domínio do mal, dado que este último é encontrado num ser dotado de liberdade. No início da passagem, ele fala em extermínio do mal, depois (em vista de esse extermínio não ser possível, mediante forças humanas), passa a falar na necessária possibilidade de um domínio do mesmo - o que deixa entrever que, embora o mal não possa ser exterminado, é necessário admitir a possibilidade de ele vir a ser dominado e, que, assim, tal domínio representa um avanço do ponto de vista moral. A necessidade de se pensar tal possibilidade (do domínio do mal) se explica, por um lado (e num sentido amplo) pelo próprio foco da investigação moral kantiana, aquele da edificação do humano mediante a consciência da lei moral e, por outro, por força de Kant conceber o humano como um ser que age livremente. A não admissão da possibilidade do domínio do mal resultaria em desqualificar a liberdade, quer (num sentido genérico) enquanto capacidade de escolha, quer (no sentido prático negativo) enquanto capacidade de agir independentemente das inclinações. O ponto de Kant, contudo, não é discutir a necessidade da admissão da possibilidade do domínio do mal, mas quais são as condições de efetividade de tal domínio, ou seja, como ele pode ser operado no interior de uma intenção corrompida. No que tange propriamente à possibilidade do domínio do mal, ela tem a sua plausibilidade afiançada em vista

11 “[...] der Mensch ist böse, kann [...] nichts anders sagen wollen als: er ist sich des moralischen Gesetzes bewußt und hat doch die (gelegenheitliche) Abweichung Von demselben in seine Maxime aufgenommen".

${ }^{12} \mathrm{O}$ uso da liberdade está vinculado quer à necessidade em admitir a possibilidade de domínio do mal, quer às condições de efetivação dessa possibilidade propriamente dita. 
de dois pressupostos: o primeiro remete ao fato de a disposição para o bem ser originária e, portanto, vinculada mais solidamente ao homem; outro, enfatizado por Kant explicitamente, concerne ao fato de que o conflito entre o bem e o mal e a sobreposição deste último se dão no interior de um ser dotado de liberdade ${ }^{13}$.

O problema que aqui nos propomos investigar não se impõe, por consequência, em dependência do caráter inextirpável do mal, mas como Kant, na medida em que enfatiza a possibilidade do domínio do mesmo, argumenta no sentido de articular como tal domínio é possível frente à corrupção da máxima suprema ou intenção pelo mal. Assim, Kant, para além de evidenciar a necessidade de se admitir a possibilidade de domínio do mal, se empenha em demonstrar em que termos tal domínio pode se apresentar. Daí que, a rigor, o que será objeto de investigação é a cisão do "compromisso" da intenção humana com um modo de abordar a lei que resulta no mal moral, pois é a partir disso que se delineia o que Kant denomina domínio do mal, o qual frutifica no restabelecimento do bem.

\title{
II- A ÁRVORE BOA QUE PRODUZ MAUS FRUTOS
}

Ao se dedicar a tematizar o progresso moral humano, Kant se serviu da metáfora da "árvore boa que produz maus frutos" e dela extraiu o máximo que pode, apresentando dois argumentos. No primeiro, a metáfora da árvore é empregada no sentido de demonstrar que não há incompatibilidade entre o mal moral agregado ao homem e a possibilidade do progresso:

\begin{abstract}
Mas conforme a declaração [Geständnisse] anteriormente proferida, uma árvore originariamente boa (segundo a disposição) produziu frutos ruins e o declínio do bem no mal (quando se considera que o mal provém da liberdade) não é mais concebível do que o reerguimento do mal para o bem. Assim a possibilidade desse último não pode ser negada. ${ }^{14}$ (Rel, 1793,45).
\end{abstract}

O argumento decorre nos seguintes termos: assim como se admite que uma árvore boa produza maus frutos, também deve ser reconhecida a afirmação de que uma árvore má possa render bons frutos. Abstraindo-se do tom metafórico, o que Kant pretende dizer é o seguinte: se o homem, mesmo sendo detentor de uma

13 " $\mathrm{Da}$ aber doch nach dem vorher abgelegten Geständnisse ein ursprünglich (der Anlage nach) guter Baum arge Früchte hervorgebracht hat und der Verfall vom Guten ins Böse (wenn man wohl bedenkt, da $\beta$ dieses aus der Freiheit entspringt) nicht begreiflicher ist, als das Wiederaufstehen aus dem Bösen zum Guten: so kann die Möglichkeit des letztern nicht bestritten werden”.

14 "Der der Anlage nach gute Baum ist es noch nicht der That nach; denn wäre er es, so könnte er freilich nicht arge Früchte bringen; nur wenn der Mensch die für das moralische Gesetz in ihn gelegte Triebfeder in seine Maxime aufgenommen hat, wird er ein guter Mensch (der Baum schlechthin ein guter Baum) genannt." 
disposição originária para o bem, produziu maus frutos, isto é, submeteu a suficiência da lei moral aos móbiles advindos das inclinações, então é viável a admissão de que a natureza humana corrompida pelo mal possa render bons frutos, ou seja, restabelecerse moralmente, mediante a tomada da lei moral como um móbil suficiente.

Kant, com essa metáfora, pretende ter provado a possibilidade de o homem transitar da ruína para o melhoramento moral. Não obstante, é por suposto necessário entender por que o bem originário ao homem não impediu a corrupção pelo mal (isto é, por que a árvore boa não produziu bons frutos). Nesse sentido, e ainda se servindo da metáfora da árvore, ele expõe outro argumento:

\begin{abstract}
A árvore boa segundo a disposição não o é ainda segundo o ato; pois se o fosse, certamente, não poderia produzir frutos ruins. Somente quando o homem acolher na sua máxima o móbil nele assentado para a lei moral poderá ser denominado um homem bom (a árvore pura e simplesmente uma árvore boa). ${ }^{15}$ (Rel, 1793,45 , nota).
\end{abstract}

Do fato de o homem ser disposto para o bem não se segue que ele seja efetivamente bom. O homem só será passível de ser considerado bom, quando admitir na sua máxima a lei moral como móbil suficiente. Por isso, o bem se constitui em uma disposição, uma suscetibilidade para adotar a lei moral como um móbil suficiente para a ação. Se o fato de o homem possuir uma disposição para o bem acarretasse que ele fosse bom, então ele não produziria maus frutos, porque nada de mal poderia se enxertar na sua intenção. Utilizando a dinâmica potência e ato, Kant explica por que o homem se deixou corromper pelo mal, no entanto, resta em aberto entender se com tal corrupção o bem não foi expatriado da natureza humana. Daí a grande utilidade do fato de o bem ter sido concebido enquanto originário, uma vez que, porquanto tal caráter primitivo ao homem não tenha evitado a sua decadência, pelo menos garante, por um lado, que o homem, mesmo estando mergulhado no mal, não deixe de conter a presença do bem e, por outro, mantenha, em linhas gerais, a possibilidade do progresso moral. Forçoso é que Kant, a despeito dos fortes indícios no que tange à maldade humana, não poderia deixar de conceber a disposição para o bem como algo mais característico do homem do que a propensão para o mal, visto que isso redundaria em retirar ou tornar inútil a condição do homem de agente da moralidade: do que serviria ser detentor e consciente da lei moral, se isso não representasse um

15 "O restabelecimento [Wiederherstellung] da disposição originária para o bem em nós, não é, portanto, aquisição de um móbil para o bem perdido; pois tal móbil, que se constitui no respeito pela lei moral, nós jamais podemos perder e, se isso fosse possível, nunca o obteríamos novamente" (Rel, 1793, 46). ["Die Wiederherstellung der ursprünglichen Anlage zum Guten in uns ist also nicht Erwerbung einer verlornen Triebfeder zum Guten; denn diese, die in der Achtung fürs moralischr Gesetz besteht, haben wie nie verlieren können, und wäre das letztere möglich, so würden wir sie auch nie wieder erwerben']. 
mínimo de comprometimento entre o homem e o bem? O fato de o homem ser originariamente disposto para bem, porquanto não resulte muito utilitário quanto ao bom desempenho moral humano (já que Kant não se esquiva de afirmar que o homem é mau) é bastante conveniente na argumentação sobre a possibilidade de um progresso moral, descrito por ele nos termos de um resgate, porque se trata tão-somente de uma revitalização de um bem que já está contido no humano e não de uma apropriação de algo exterior a ele.

\section{III- O RESGATE DO BEM: REVOLUÇÃO E REFORMA GRADUAL}

Kant, pela metáfora da árvore, prova genericamente a plausibilidade do resgate do bem. Resta saber, agora, a partir de que meios se opera tal resgate. Cabe dizer que, estabelecido que a intenção (máxima suprema ou primeiro fundamento subjetivo) está corrompida e se acrescentando que ela é única, no sentido de que não podemos fundar ou estabelecer outra máxima suprema (agora boa) que com ela rivalizasse, o progresso moral deve se edificar nos termos de uma reabilitação ou conversão de tal máxima corrompida para uma máxima boa.

Vimos, por um lado, que a disposição originária para bem não representa a aquisição do próprio bem e, por outro, que, mesmo corrompido pelo mal, o homem não deixa de deter o gérmen do bem. Consequentemente, o progresso moral humano, o domínio do mal, se dá nos termos de um resgate ou revitalização do bem. O restabelecimento da disposição originária para o bem não acontece, segundo Kant, com a recuperação de um móbil perdido, visto que a reverência pela lei moral nunca nos é perdida, e, se assim o fosse, jamais a conseguiríamos recuperar ${ }^{16}$. Ainda que assegure que a natureza humana está corrompida pelo mal, Kant não admite que o homem tenha abdicado da lei moral enquanto móbil. O arbítrio humano, seja em que circunstâncias for, não rechaça a lei moral. O mal moral não é concebido por um desprezo pela lei, mas pela sua subordinação como móbil suficiente a móbiles exteriores ao campo da moralidade. Assim, o restabelecimento da disposição para o bem consiste numa sobreposição da lei moral em detrimento dos móbiles advindos da sensibilidade ${ }^{17}$.

\footnotetext{
${ }^{16}$ Kant não afirma que o arbítrio humano deve renunciar às inclinações (mesmo porque isso seria impossível), mas, sim, que deve submetê-las ao valor incondicional da lei da moralidade. Tomadas em si mesmas, as inclinações não são más; entretanto, o uso que as faz suficiente para a determinação do arbítrio é mau. Qualquer móbil, com exceção da lei moral que deve ocupar esse posto, tomado como suficiente para o arbítrio, torna-se fomentador do mal.

17 "Sie ist also nur die Herstellung der Reinigkeit desselben, als obersten Grundes aller unserer Maximen, nach welcher dasselbe nicht blo $\beta$ mit andern Triebfedern verbunden, oder wohl gar diesen (den Neigungen) als Bedingungen untergeordnet, sondern in seiner ganzen Reinigkeit als für sich zureichende Triebfeder der Bestimmung der Willkür in dieselbe aufgenommen werden soll".
} 
Ele é, portanto, apenas a restauração [Herstellung] da pureza [da lei] como fundamento supremo de todas as nossas máximas, segundo a qual a lei deve ser acolhida na determinação do arbítrio não só meramente reunida a outros móbiles, ou ainda subordinada a eles (às inclinações) como condições, mas, sim, em toda a sua pureza como um móbil por si suficiente. ${ }^{18}$ (Rel, 1793, 46).

Kant propõe como meio para o resgate da disposição originária para o bem uma revolução e uma reforma gradual (Cf. Rel, 1793, 47). A revolução atua em nível intencional ${ }^{19}$, ou seja, concerne ao caráter da intenção ou máxima suprema; a reforma gradual, por sua vez, diz respeito ao agir propriamente dito. De acordo com Kant, a revolução deve anteceder a reforma, visto que "[...] a formação moral do homem não deve começar pela melhoria dos costumes, mas pela transformação na maneira de pensar [Denkungsart] e pela fundação de um caráter"20 (Rel, 1793, 48). A melhoria moral deve, em princípio, atuar sobre a intenção humana para com a lei moral enquanto móbil suficiente do arbítrio e somente, num segundo momento, ser direcionada para uma mudança de costumes. Kant justifica esse procedimento de anteceder o "pensar" ao "agir", salientando que a mudança no modo de agir não decorre necessariamente da tomada da lei moral como um móbil suficiente, mas, em geral, se dá em vista de fins exteriores ao campo da moralidade.

A mudança nos costumes, propiciada por uma reforma gradual, atua no plano da ação (da legalidade); já a mudança de ânimo, que deve antecedê-la, atua no plano da adoção das máximas. São esses dois fatores desenvolvidos que tornam o resgate da disposição originária para o bem possível. Se permanecesse apenas a mudança nos costumes, o homem agiria somente conforme o dever

${ }^{18}$ Quanto à mudança proposta em nível intencional, convém logo perguntar: por que uma revolução [Revolution]? Na busca por uma resposta, poderíamos partir do que já foi considerado, por exemplo, por Alexis Philonenko, que é de opinião que o fato de se assumir que o homem é inteiramente mau facilita a ideia da "revolução", porque não existe uma "revolução" parcial, mas ela se dá sempre de modo total. "Tudo se passa [segundo Philonenko] $<<$ como se $>>$ o homem fosse inteiramente mau por natureza. E é precisamente por isso que uma regeneração ou graça é possível. A regeneração como a graça é total - ou ela não existe" ["Tout se passe $<<$ comme si $>>$ l'homme était tout entier mauvais par nature. Et c'est précisament pour cela qu'une régénération ou une grâce est possible. La régénération, comme la grâce, est totale - ou elle n'ést pas']. (1981, p.231). J-Louis Bruch segue essa mesma linha, remetendo à ideia de totalidade, para justificar o recurso à revolução: "A conversão é necessariamente uma revolução, como, aliás, teria sido a própria queda: um homem não pode ser mais ou menos puro; todo o defeito de pureza é impureza" ["La conversion est nécessariament une revolution, comme l'avait d'ailleurs été la chute elle-memê: um homme ne peut être plus au moins pur; tout défaut de pureté est impureté’] (1968, p.81).

19 “[...] da $\beta$ die moralische Bildung des Menschen nicht von der Besserung der Sitten, sondern von der Umwandlung der Denkungsart und von Gründung eines Charakters anfangen müsse [...]"

20 " [...] denn zwischen der Maxime und der That ist noch ein großer Zwischenraum [...]" 
(seguindo a letra da lei) e não por dever, de modo genuinamente moral. Em contrapartida, sendo desenvolvida tão-somente a mudança intencional sem alguma consequência verificada no domínio empírico, tal mudança resultaria falsa, uma vez que uma intenção solidamente fundada pede pela sua realização no agir. É inválido o agir sem querer, isto é, realizar a ação apenas conforme a lei moral, sem tomá-la como móbil suficiente, assim como querer sem fazere, ou seja, permanecer num campo estritamente intencional, sem fazer qualquer esforço para realizar essa intenção. Isso, inclusive, desmistifica a ideia de alguns leitores que acreditam que a ética kantiana propõe um procedimento moral que atua estritamente no campo intencional. Não há dúvidas de que a questão central é essa; porém, Kant não limita a sua ética a um plano inteiramente inteligível. Todo o caráter moral advém, num primeiro momento, da intenção do sujeito, mas, num segundo momento, leva em consideração também o seu desdobramento no campo empírico, que, por sua vez, legitima o "vigor" da intenção.

É por meio de uma revolução (que consiste na tomada da lei moral como um móbil suficiente para o arbítrio) que se encaminha a restauração do bem originário inerente à natureza humana. Kant é bastante rigoroso na sua argumentação, ao pressupor que, como a lei moral foi tomada como um móbil suficiente por si só (isto é, uma vez instaurada a "revolução"), o homem é tãosomente suscetível ao bem. Ele não é ainda efetivamente bom, porque "[...] entre a máxima e o ato há ainda uma grande lacuna”" (Rel, 1793, 46). Daí a necessidade de uma conjunção com a reforma gradual num contínuo cultivo em busca do aprimoramento dos costumes.

Quando ele [o homem] inverte, através de uma única decisão imutável [durch eine einzige unwandelbare Entschließung], o fundamento supremo das suas máximas, mediante o qual ele foi um homem mau (e com isso se veste de um novo homem) então, é conforme o princípio e a maneira de pensar, um sujeito suscetível ao bem; mas somente será um homem bom mediante o agir e devir: i.é, ele pode esperar que com uma tal pureza do princípio que adotou para a máxima suprema do seu arbítrio, e pela firmeza do mesmo, se encontre no bom caminho (embora estreito)de um contínuo avanço do pior para o melhor [Scblechten zum Bessern]. ${ }^{21}$ (Rel, 1793, 47-48).

Tomando como base essa passagem, parece precipitada a afirmação de J.-Louis Bruch, segundo a qual "[...] para Kant [...] a conversão apaga de tal

21 "Wenn er den obersten Grung seiner Maximen, wodurch er ein böser Mensch war, durch eine einzige unwandelbare Entschließung umkehrt (und hiemit einen neuen Menschen anzieht): so ist er sofern dem Princip und der Denkungsart nach ein fürs Gute empfängliches Subject; aber nur in continuirlichem Wirken und Werden ein guter Mensch: d.í. er kann hoffen, da $\beta$ er bei einer solchen Reinigkeit des Princips, welches er sich zur obersten Maxime seiner Willkür genommen hat, und der Festigkeit desselben sich auf dem guten (obwohl schmalen) Wege eines beständigen Fortschreitens vom Schlechten zum Besssern befinde." 
modo a queda, que é bem difícil de reconhecer ainda como pecador o homem regenerado"22 (1968, p.89). Kant, por seu turno, afirma que a "revolução" (primeira fase da conversão) permite que o homem se torne suscetivel ao bem e que, somente mediante a constante "prática" desse bem (numa integração com a reforma gradual), ele poderá ser considerado um homem bom. Conforme veremos, o labor em prol do aperfeiçoamento moral é algo que não se esgota facilmente, porque, sendo detentor de uma propensão para transgredir o correto acolhimento da lei, o homem vive permanentemente à sombra do mal.

\section{IV- REVOLUÇÃo E ARBÍTRIO}

O cerne da reabilitação moral humana é por Kant situado no redirecionamento da recepção da lei moral no interior da intenção humana, o qual é efetivado mediante uma revolução. Resta, com efeito, delimitar em que termos tal revolução é operada, dada a corrupção da intenção ou máxima suprema pelo mal. A revolução, Kant a emprega nos termos de uma ruptura com a maneira de acolher a lei que resulta no mal. Mas, como tal revolução é possível de ser operada, no interior da intenção que está comprometida ou habituada com esse modo ilícito de atuar? Isto é, como a intenção pode mudar de índole, tendo em vista a sua característica de manter-se fiel a um determinado modo de abordar a lei? Kant, cabe dizer, não se detém em esclarecer essa problemática a fundo. Ele, aliás, quando avalia a possibilidade da efetivação da revolução na intenção humana, emprega um argumento bastante truncado, enigmático e não muito persuasivo. Trata-se, contudo, de um princípio que, apesar de sua frugalidade, carrega consigo o cerne da especulação moral kantiana. Ele se expressa na proposição "dever é poder", cuja profecia é que, em detrimento das precárias condições humanas frente à moral, mesmo assim cabe ao homem progredir, porque o dever não ordenaria algo que não pudesse ser cumprido. Ou seja, dado que o progresso se the apresenta como um "dever", então se supõe que ele detém o "poder". Nas palavras do próprio Kant: "Pois se a lei moral prescreve que devemos agora ser homens melhores, segue-se inevitavelmente que precisamos também poder sê-lo"233 (Rel, 1793,50).

Com efeito, a proposição "dever é poder" não abarca, sustenta ou dá conta de neutralizar toda a argumentação acerca do declínio do homem ao mal. Kant, a bem da verdade, não poupou tinta nem vocabulário para descrever a maldade inerente à natureza humana e, nesse seu fazer, quase que deixou inviável

22 “[...] alors que pour Kant la conversion efface tellement la chute qu’il est bien difficile de reconnaitre encore comme pécheur l'homme regénéré”.

23 "Denn wenn das moralische Gesetz gebietet: wir sollen jetzt bessere Menschen sein, so folgt unumgänglich: wir müssen es auch können”.

Trans/Form/Ação, Marília, v. 34, n. 2, p. 53-70, 2011 
a possibilidade de uma melhoria moral. Ocorre que a argumentação kantiana parece ser mais concisa ao descrever a maldade intrínseca ao homem do que ao explicitar a possibilidade de um progresso ou reabilitação do humano. Os rigorosos termos e aparato conceitual, a partir dos quais ele articulou a relação entre o mal e a natureza humana, soam quase que intransponíveis no momento de tecer a possibilidade de uma superação do mal rumo ao bem. Há, por assim dizer, uma defasagem na energia ou robustez argumentativa impressa no momento da descrição da ruína moral com relação àquele da reabilitação ou resgate do bem. Enfim, a proposição “dever é poder" não conduz consigo a compreensão de como a revolução é instaurada perante o compromisso representado pela intenção com um determinado modo de atuar que implica o mal.

Não se pode afirmar, no entanto, que essa questão padece de uma insuficiência argumentativa, como se Kant estivesse desprovido de instrumentos para explicitar como se opera a revolução. Ele, ao que tudo indica, não se interessou em tratar a fundo esse problema (preferindo se servir da proposição "dever é poder"), mas disso não se segue que não se possa recorrer a pontos intrínsecos à sua teoria moral, para melhor explicitar a revolução. Nesse sentido, é interessante reconstruir (ainda que em linhas gerais) o argumento de Edgar Jorge Filho, cujo maior mérito é de ir além da proposição “dever é poder", mantendo, com efeito, as suas bases argumentativas em "solo" kantiano. O comentador se vale do conceito de livre-arbítrio como o arbítrio que pode ser determinado pela razão pura, mas não o é necessariamente, e com ele pretende provar que o arbítrio não se compromete em definitivo com as máximas que adota (sejam elas de que gênero for). Com base na afirmação kantiana de que "[...] fora da máxima, não se deve nem se pode indicar qualquer fundamento de determinação do livre-arbítrio" ${ }^{24}$ (Rel, 1793, 21, nota), Jorge Filho alega que a determinação do livre-arbítrio cabe às máximas, sendo elas moralmente boas ou não. Fica excluída, por um lado, a necessidade da determinação do livre-arbítrio por máximas em conformidade com a razão pura; por outro lado, também é excluída a impossibilidade de ele ser determinado por máximas boas, de modo que, por ele não ser necessariamente influenciado por essas máximas, não se segue que a sua capacidade de "vir a ser" seja alienada. "Portanto [diz Jorge Filho], o livrearbítrio não se compromete necessariamente com nenhuma máxima, moral ou imoral. Isso significa também que toda a máxima adotada, ainda que com extrema firmeza, pode ser abandonada" (JORGE FILHO, 2000, p.94). Isso, observa o comentador, vale também para a máxima suprema, nos seguintes termos:

24 “ $[\ldots]$ außer der Maxime aber kein Bestimmungsgrund der freien Willkür angeführt werden soll und kann [...]" 
[...] enquanto rigorosamente "primeira", a máxima fundamental não poderia ser condicionada por qualquer outra máxima; daí que ao adquiri-la (pois toda a máxima é adquirida) o livre-arbítrio não se determinaria por nenhuma máxima, sendo-lhe de certo modo possível atuar sem regra. Ter-se-ia que admitir a possibilidade desta irregularidade do livre arbítrio para a possibilidade da aquisição da máxima fundamental e também da revolução desta. (JORGE FILHO, 2000, p.94).

Com efeito, é desnecessário ir tão longe, ou seja, mencionar uma irregularidade do arbítrio, para salvaguardar a possibilidade da intenção ou mesma suprema ser revolucionada. $O$ argumento de que o arbítrio não se compromete em definitivo com um determinado modo de atuar (porque ele detém a propriedade de poder ser ou não determinado de certa maneira) já é suficiente para a compreensão da revolução da intenção. Em sendo uma máxima, a intenção estaria, por assim dizer, submetida ao operar do arbítrio, assim como as outras máximas, quer dizer, poderia ser refeita, o que em nossa argumentação se converte em uma revolução. Esta última é possível, portanto, em dependência da capacidade do arbítrio em aderir ou não a uma forma de se determinar no domínio moral. Isso, aliás, explicita a seguinte afirmação kantiana a respeito do mal: “[...] não obstante é preciso ser possível dominá-lo [überwiegen], porque se encontra no homem como um ser que age livremente"25 (Rel, 1793, 37).

A revolução, contudo, não pode ser admitida como algo que se opera facilmente, pois a intenção não é uma simples máxima, mas uma máxima suprema e, por conseguinte, carrega consigo certas peculiaridades. Sustentar tão-somente que o arbítrio não se compromete com nenhuma máxima (boa ou má) se choca diretamente com a ideia da intenção moral concebida como "[...] o primeiro fundamento subjetivo da adoção de máximas”, que só pode ser único e referir-se "[...] universalmente ao uso integral da liberdade". O argumento nesses termos, e sem qualquer reparo, poderia ceder espaço ao latitudinarismo tanto sincretista quanto indiferentista - o que é rejeitado por Kant. O comprometimento que a máxima suprema representa não permite que o acolhimento da lei seja manipulado de modos opostos, no interior da conduta do agente. A revolução se relaciona a uma mudança que abrange a esfera comportamental universal do agente, quer dizer, compreende a sua conduta de vida. Se o agente admite a lei como móbil suficiente da sua máxima, ele não pode imediatamente destituir tal lei desse status e depois reassumir tal posição, como se isso não implicasse um grande esforço de compreensão do que se está fazendo - como se esses modos de abordagem da lei fossem conciliáveis. O resgate do bem, Kant enfatiza, pede por uma revolução, e o argumento de Jorge Filho esclarece em muito a viabilidade de tal revolução;

25 "[...] gleichwohl aber muß er zu überwiegen möglich sein, weil er in dem Menschen als frei handelndem Wesen angetroffen wird". 
todavia, devemos tomar essa capacidade do arbítrio de "mudar" de máxima suprema como algo não-corriqueiro, isto é, um exercício possível, mas não trivial ou frequente, sem que isso, no entanto, impeça uma nova mudança de direção.

\section{V - MAL, APERFEIÇOAMENTO MORAL E VIRTUDE}

A forma pela qual é explicitado o resgate do bem reflete nos termos e condições com base nos quais se pode conceber o aperfeiçoamento ou progresso moral humano. Conforme o pressuposto de que é inerente à qualidade do arbítrio poder rever o seu compromisso com a máxima suprema, segue-se que, uma vez resgatado o bem no interior da intenção, isto é, uma vez edificado um comprometimento com a tomada da lei moral como móbil suficiente, tal pacto não é definitivo. Tudo indica, portanto, que uma nova corrupção pelo mal é possível, pois, quanto ao caráter moral humano, nada é definitivo, uma vez que ele pode arbitrar. Forçoso é que Kant, a propósito da revolução em prol do bem, observa:

Quando ele [o homem] inverte, através de uma única decisão imutável [durch eine einzige unwandelbare Entschließung], o fundamento supremo das suas máximas, mediante o qual ele foi um homem mau (com isso se veste de um novo homem). ${ }^{26}$ (Rel, 1793, 47).

Provavelmente é tomando como ponto de referência essa passagem, em que Kant menciona "uma única decisão imutável", que Olivier Reboul fez a seguinte observação: "Nesse domínio, que não é aquele dos atos, mas da intenção mais íntima, uma vez significa uma vez.por todas" ${ }^{27}$ (1971, p.82). Ora, se fosse assim, quer dizer, que uma vez significasse uma vez por todas, seria deveras difícil de o homem reorientar a sua conduta, e desse conceber, duas questões entre si contraditórias se imporiam, no interior da argumentação: por um lado, e sob o pressuposto da corrupção pelo mal, o resgate do bem seria impossível, porque primeiramente o homem "optou" no interior da sua intenção pelo mal, ou seja, subordinou a lei moral a outros móbiles; por outro lado, se a "decisão única imutável" valesse tãosó para o restabelecimento do bem, a imputabilidade humana seria prejudicada, visto que não teria mais possibilidades de agir mal. Essa "única decisão imutável”, portanto, deve conter outro sentido que não aquele de uma decisão definitiva e inabalável, como se, uma vez efetivado o bem na intenção humana, a possibilidade da corrupção pelo mal fosse abolida. Aliás, o próprio Kant enfatiza:

26 "Wenn er den obersten Grung seiner Maximen, wodurch er ein böser Mensch war, durch eine einzige unwandelbare Entschließung umkehrt (und hiemit einen neuen Menschen anzieht).”

27 "Dans ce domaine, que n'est pas celui des actes mais de l'intention la plus intime, une fois signifie une fois pour toutes". 


\begin{abstract}
A luta, que nessa vida, todo o homem bem intencionado precisa vencer sob a direção do princípio bom contra os protestos [Anfechtungen] do mal, nenhuma vantagem maior pode the oferecer, quanto ele também se esforce, do que a libertação do domínio [Herrschaff] do mal. [...] Dos ataques [Angriffen] desse último, o homem não deixa de estar sempre exposto; e para defender a sua liberdade, que é continuamente combatida, ele precisa sempre ficar preparado para a luta. ${ }^{28}(\operatorname{Rel}, 1793,93)$.
\end{abstract}

O restabelecimento do bem não implica o extermínio do mal, mas o controle ou domínio do mesmo, de sorte que, assim como a disposição para o bem não se constitui no próprio bem, a propensão para o mal não é o próprio mal: mesmo que o homem reconstitua a sua intenção direcionada para o bem, ele não deixa de deter uma propensão para o mal, ou seja, ele detém ainda a possibilidade de subordinar à lei moral a móbiles exteriores à moralidade. Quando Kant menciona uma "única decisão imutável”, a "única decisão" diz respeito à revolução em prol do bem. Pela perspectiva de Francisco Herrero, a relação revolução/decisão única se explica nos seguintes: “[...] se a conversão consiste na adoção do móbil moral e esse móbil é único, a conversão só pode dar-se num ato também único" (1991, p.87). O imutável não remete aqui a algo definitivo ou inalterável, no sentido de que, uma vez o bem instaurado, não há mais a ameaça da degradação moral, mas pode ser explicitado em dois sentidos atinentes ao conteúdo ou princípio de tal revolução: imutável pode se referir ao fato de se ter operado uma revolução, quer com referência ao que se passou, quer quanto ao futuro moral humano, e disso se segue a consciência da necessidade de uma luta permanente para manter o cerne dessa revolução (a consideração da lei como móbil suficiente para o arbítrio), a fim de evitar uma recaída no mal. Imutável, ainda, pode se referir ao princípio do dever-ser que pede pela efetuação e manutenção de tal revolução em busca do aperfeiçoamento moral humano.

O fundamental, contudo, nessa investigação que aqui nos propomos, é desvincular a noção de "decisão ou revolução imutável" de uma significação determinística, por um motivo básico: salvaguardar a postura moral do homem nos limites do humano, não transformá-lo em um santo, o que redunda na preservação da própria noção de virtude. Ao homem, segundo os pressupostos kantianos, só cabe ser virtuoso se ele detém a capacidade de ser mau, agir de modo a sujeitar a suficiência da lei moral a móbiles exteriores à moralidade.

28 "Der Kampf, den ein jeder moralisch wohlgesinnte Mensch unter der Anführung des guten Princips gegen die Anfechtungen des bösen in diesem Leben bestehen muß, kann ihm, wie sehr er sich auch bemüth, doch keinen größen Vortheil verschffen, als die Bfreiung ven der Herrschaft des letzern. [...] Den Angriffen des letztern bleibt er nichts destoweniger noch immer ausgesetzt; und seine Freiheit, die beständig angefochten wird, zu behaupten, mu $\beta$ erforthin immer zum Kampfe gerüstet bleiben.” 
A virtude desempenha, com efeito, uma ligação entre a perfeição do dever perante a fragilidade do agente moral humano (ou outro tal como ele) de aderir espontaneamente aos ditames da moral. A virtude, Kant a insere como um degrau a ser galgado para que o homem alcance a conduta que moralmente lhe é cabida. Ela é um meio estritamente humano, mediante o qual o sujeito se educa para o cumprimento do seu dever moral. Tanto que, segundo o comentário de Allen Wood, "[...] não pode ser confiável o cumprimento do dever sem (algum grau de) virtude"29 (1999, p.330). Ou seja, toda a ação por dever (no âmbito humano) encontra obstáculos para ser efetivada e, portanto, comporta uma luta.

\begin{abstract}
Virtude [diz Kant] é a força das máximas do ser humano na observância de seu dever. Toda a força pode ser reconhecida somente pelos entraves que ela pode superar; na virtude esses obstáculos são inclinações naturais, as quais podem entrar em conflito com o propósito moral do homem $[\ldots]^{30}$ (MS, 1797, 394).
\end{abstract}

A virtude ou a "disposição moral em luta" (tal como é definida na Crítica da razão prática $)^{31}$, Kant a caracteriza, sobretudo, nos termos de uma "força" ou "intenção deliberada de resistir". Trata-se, assim, de uma resistência empregada contra algo em favor de outra coisa: nesse caso, uma resistência ao mal em nome de uma conduta moralmente boa. Kant, pois, define o "campo de atuação" da virtude em dependência do conflito (da escolha em agir de determinada maneira e não de outra), de maneira que ela não se manifesta quando só existe uma alternativa, quando não há possibilidade de escolher diferentemente do que é proposto. Para que haja virtude, é necessário, por conseguinte, conflito, desordem, dilema e, enfim, escolha, de sorte que a virtude resulta sempre na submissão de algo em favor de outra coisa.

PINHEIRO, L. M. Kant and the ransom of the good in the fallen human nature. Trans/Form/Ação, Marília, v. 34, n.2, p. 53-70, 2011.

ABSTRACT: This article has as purpose to examine the Kant's argument with relationship to of the possibility restoration of good in face of radical evil in human nature. The study proposed here takes

29 “[...] can be no reliable fulfillment of duty without (some degree of) virtue".

30 "Tugend ist die Stärke der Maxime des Menschen in Befolgung seiner Plicht. - Alle Stärke wird nur durch Hindernisse erkannt, die sie überwältigen kann; bei der Tugend aber sind diese die Naturneigungen, welche mit dem sittlichen Vorsatz in Streit kommen können [...]"

31 Cf. KpV, 2002, 150-151. 
as its starting and central point to Kant's affirmation that the intention or supreme maxim is corrupted by evil, and seeks, from the consequences of such finding and arguments provided by Kant, outline the possibilities and character of the restoration of good in the within such intention.

KEYWORDS: Good. Evil. Intention. Moral progress.

\section{REFERÊNCIAS}

BRUCH, Jean-Louis. La philosopbie religieuse de Kant. Paris: Aubier-Montaigne, 1968.

HERRERO, Francisco Javier. Religião e história em Kant. Trad. de José Ceschin. São Paulo: Loyola, 1991.

JORGE FILHO, Edgard José. O mal radical e a possibilidade da conversão ao bem. Studia Kantiana. Rio de Janeiro: Imprinta, p.87-104, 2000.

KANT, Immanuel. Die Religion innerhalb der Grenzen der bloßen Vernunft, 1793. (Akademie Textausgabe, Bd. VI).

. Die Metaphysik der Sitten. (Akademie Textausgabe, Bd. VI), 1797.

. Kritik der praktischen Vernunft. Tradução de Valerio Rohden (baseada no original de 1788). São Paulo: Martins Fontes, 2002. (Akademie Textausgabe, Bd. V).

MICHALSON, Gordon E. Fallen freedom. Kant on the radical evil and moral regeneration. Cambridge: Cambridge University Press, 1990.

PHILONENKO, Alexis. L'oeuvre de Kant. La philosophie critique. Tome II. Morale et politique. Paris: Vrin, 1981.

REBOUL, Olivier. Kant et le probléme du mal. Prefácio de Paul Ricoeur. Montréal: Les Presses de l’Université de Montréal, 1971.

WOOD, Allen W. Kant's Ethical Thought. Cambridge: Cornell University Press, 1999.

Recebido em 22 de março de 2011

Aprovado: em 5 de junho de 2011 